\title{
Academic Library Buildings
}

Interior, main reading room, St. John's University Library (right); Library Institute for Advanced Education (center); exterior, Hofstra University Library (below).
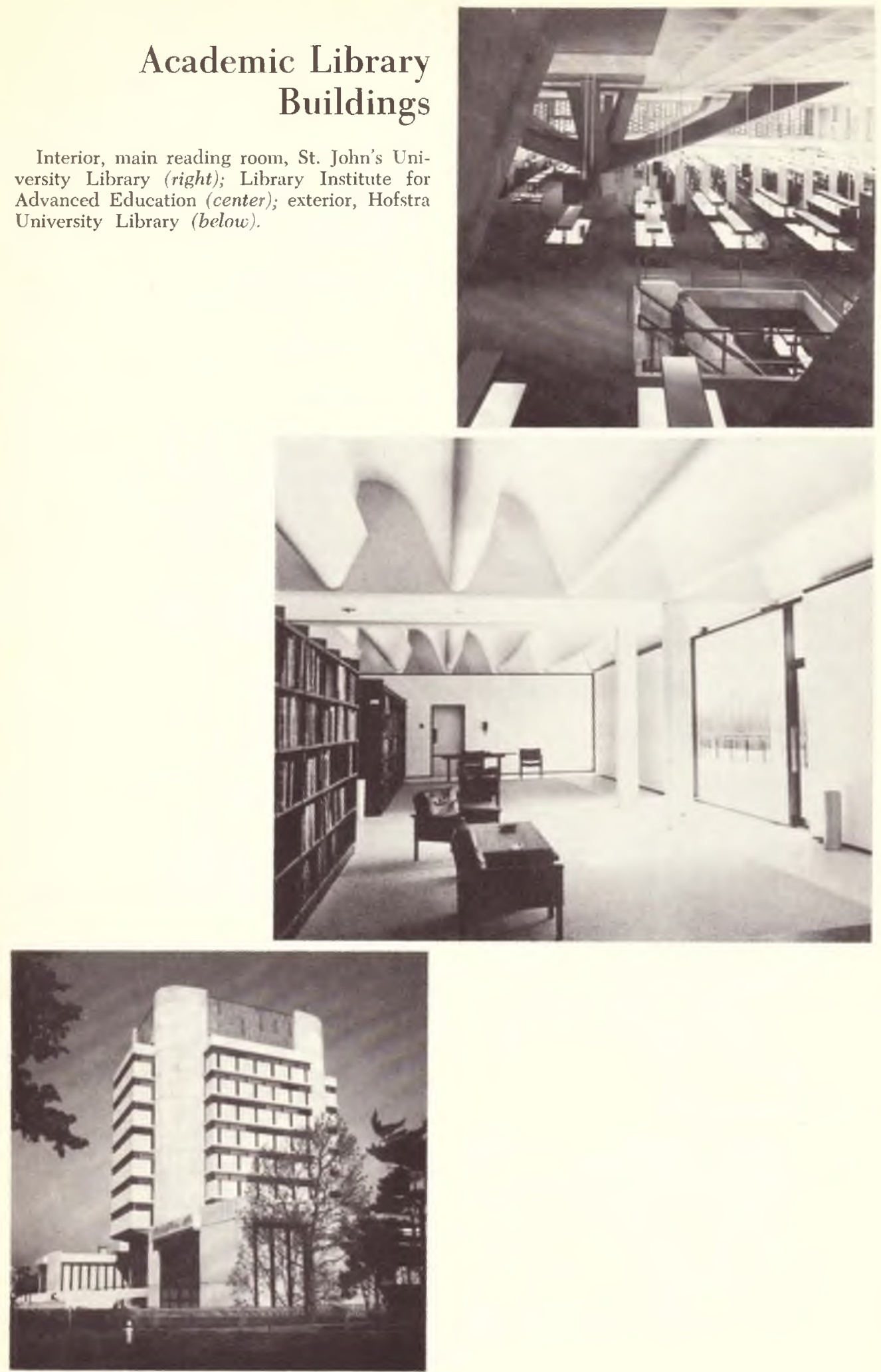
An Important Supplement and

\author{
Two New Manuals \\ from the Publishing Department of the
}

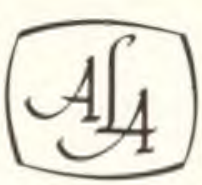

American

Library

Association

\title{
Guide to Reference Books, 8th edition First Supplement, 1965-1966
}

Brings Winchell's indispensable Guide up to date with annotated descriptions of more than 1,000 reference works in all fields published during the 1965-66 period. New works, new editions of works previously listed, and new parts of continuations are listed. Titles from the basic volume are included only if they incorporate new material, textual changes, or title changes. New features of the listings in this supplement are inclusion of $\mathrm{LC}$ card numbers and references to reviews in selected A.L.A. periodicals. As in the earlier supplements to previous editions, prices are given. Cross references to the basic volume. Completely indexed. Eugene P. Sheehy. Ready. $\$ 3.50$

\section{Personnel Organization and Procedure}

A Manual Suggested for Use in

College and University

Libraries Second Edition

Public Libraries

Second Edition

Written as if they were actual persomnel manuals, these theoretical models provide a framework for administrators preparing their own statements. The systematic coverage given the basic principles and procedures of sound personnel administration also allows for easy modification to fit local circumstances. Among the topics covered are: organization and administration; classification of positions; salary schedules; performance evaluations; working conditions; and staff relationships. The imaginative and practical approach in these revisions of the 1952 editions will simplify the work of administrators in producing their own manuals.

Library Administration Division, A.L.A. Ready.

Each, $\$ 2.50$

\section{Recent titles}

The Abbreviated Citation. ACRL Monograph $28 \quad \$ 2.25$

Books for Children, 1966-1967 \$2.25

Guides to Newer Educational Media, 2d. ed. $\$ 1.50$

Lasting Books 1944-1964 50 copies $\$ 4 \quad 100-\$ 7 \quad 250 — \$ 15 \quad 500-\$ 25$

Libraries: Building for the Future $\$ 4.50$

Standards for Library Services for the Blind and Visually Handicapped $\$ \mathbf{\$ 1 . 7 5}$

50 East Huron Street, Chicago, 60611 